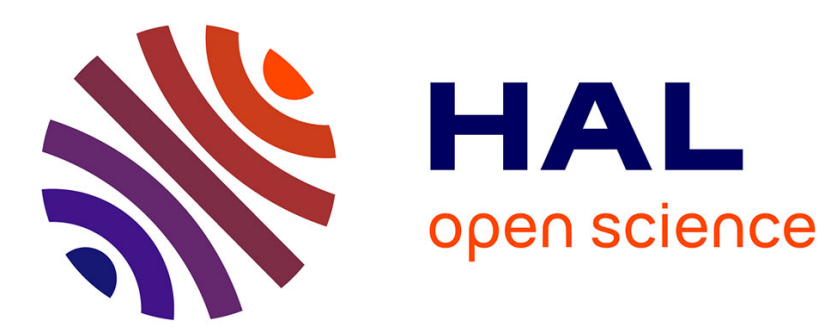

\title{
Adaptation of the STICS model to subsurface drained soils
}

Julien Tournebize, Cyril Kao, Nenad Nikolic, Daniel Zimmer

\section{To cite this version:}

Julien Tournebize, Cyril Kao, Nenad Nikolic, Daniel Zimmer. Adaptation of the STICS model to subsurface drained soils. Agronomie, 2004, 24 (6-7), pp.305-313. 10.1051/agro:2004030 . hal-00886025

\section{HAL Id: hal-00886025 \\ https://hal.science/hal-00886025}

Submitted on 1 Jan 2004

HAL is a multi-disciplinary open access archive for the deposit and dissemination of scientific research documents, whether they are published or not. The documents may come from teaching and research institutions in France or abroad, or from public or private research centers.
L'archive ouverte pluridisciplinaire HAL, est destinée au dépôt et à la diffusion de documents scientifiques de niveau recherche, publiés ou non, émanant des établissements d'enseignement et de recherche français ou étrangers, des laboratoires publics ou privés. 


\title{
Adaptation of the STICS model to subsurface drained soils
}

\author{
Julien TOURNEBIZE ${ }^{\mathrm{a} *}$, Cyril KAO ${ }^{\mathrm{a}}$, Nenad NiKOLIC ${ }^{\mathrm{a}}$, Daniel ZIMMER ${ }^{\mathrm{b}}$ \\ ${ }^{a}$ Cemagref, Drainage and Barrier Engineering Research Unit, Parc de Tourvoie, BP 44, 92163 Antony Cedex, France \\ ${ }^{\mathrm{b}}$ World Water Council, Les Docks de la Joliette, Atrium 10.3, 10 place de la Joliette, 13002 Marseille, France
}

(Received 16 July 2003; accepted 17 November 2003)

\begin{abstract}
The generic crop model STICS was modified to take into account shallow water-table fluctuations and subsurface drainage in the context of French waterlogged soils. This was accomplished by incorporating a subsurface drainage component into STICS code. The SIDRA (Simulation du Drainage) model was adapted to a daily time-step. For the dimensional aspect, the passage from two-dimensional drainage functioning to STICS one-dimensional conceptualization is done by taking an average water elevation between drain and mid-drain spacing. Simulation performances of the new STICS were evaluated by comparing its predictions with six years (1979-1983 and 1985-1986) of measured data from the field experiment of Arrou, located in northern France. Comparisons of STICS predictions with the measurements of drain-flow rates, total drained volumes and depths to water table for different crops and drain spacings were satisfactory. Nevertheless, the performances were better for drain spacings of less than $20 \mathrm{~m}$ and for winter crops or covers.
\end{abstract}

subsurface drainage / Hooghoudt's equation / crop water model / flow / water table

\section{INTRODUCTION}

In temperate climates, many shallow soils suffer from temporary waterlogging during humid seasons. In most cases, this waterlogging is a consequence of an accumulation of infiltrated rainwater above a geological or pedological "impervious" layer located close to the soil surface. Soil waterlogging is detrimental to crop yield and constitutes a major constraint for the management of 30\% of French agricultural areas [17] (artificially drained land in France is about 3 million hectares [8]). In French waterlogged-soil areas, the waterlogging period occurs from the end of fall to the beginning of spring. By reducing climate and soil constraints, agricultural drainage contributes to increasing crop yield and optimizing soil tillage. Artificial drainage efficiency depends on drainage density, i.e. the depth of the drain base and drain spacing (about $0.9 \mathrm{~m}$ and $10 \mathrm{~m}$, respectively, in the French context). It is commonly accepted that agricultural drainage strongly influences shallow watertable functioning.

Estimation of drain-flow rates and drained volumes are crucial in order to quantify water and solute fluxes and to assess agricultural and environmental impacts [2, 19]. Existing drainage models traditionally follow various approaches. Each kind of model is developed to satisfy specific objectives, which determine the nature of the model (conceptual, deterministic, etc.), and the particular assumptions used. Lorre and Lesaffre [15] distinguish four different model types on the plot scale: (1) saturated flow models; (2) unsaturated flow models; (3) satu- rated and unsaturated flow models, i.e. complete models, and (4) water balance models. In model classes 1, 2 and 3, the modeling is deterministic and based on physical local equations. Generally in water balance models (class 4), the modeling is more conceptual. Model resolution is based on analytical or semi-analytical equations or based on a numerical scheme for steady state or unsteady state. These equations are derived from the solution of Laplace or Boussinesq's equation, using appropriate assumptions. In many drainage models, a steady state relationship between water-table elevation at drain mid-spacing $(\mathrm{H})$ and drain-flow rate $(\mathrm{Q})$ is assumed to be valid regardless of the possible effects of the time-dependent recharge on this relationship. For instance, in models such as DRAINMOD [23], EPIC-WT [20], GLEAMS-SWAT [18] or RZWQM [22], drain-flow rates are predicted by Hooghoudt's equation. In models such as SWACROP [10] or SWAP [24], Ernst's equation is used. In AGRIFLUX [1] the Bouver and van Schilgaarde equation is solved.

Among them, a comparison has been done by El-Sadek et al. [7] between two different models including different approaches: SWAP and DRAINMOD. SWAP is a one-dimensional, physically-based and daily time-step model for water, heat and solute transport in the saturated and unsaturated zones, and also includes modules for simulating irrigation practices and crop growth. SWAP takes into account hysteresis for soil hydrodynamic properties and can simulate preferential flow [21]. The water transport module in SWAP calculates water flux in the soil profile by solving Richards' equation based on Darcy's law

* Corresponding author: julien.tournebize@cemagref.fr 
and by using hydraulic functions for each horizon. Drain-flow rates are calculated by applying Hooghoudt's or Ernst's equation. Moreover, SWAP distinguishes the drain-flow rate above the drain and the drain-flow rate of all the plots at the bottom profile. This is why SWAP is usually considered as a quasitwo-dimensional model [21]. On the other hand, the DRAINMOD model is based on the water balance of a thin section of soil located midway between the drains and extending from the impermeable layer to the soil surface. The percolation rate of water into the unsaturated zone from the soil surface to the top of the water table is calculated by Green and Ampt's equation. The method used to derive drainage rates is based on the assumption that lateral water movement occurs mainly in the saturated region. The drain-flow rate is also calculated by Hooghoudt's equation in steady state. When the water table rises to the surface and the surface is ponded, the DRAINMOD model switches to Kirkham's equation. The model can use different time-steps (hourly and daily). Water movements into the soil profile are vertical and depend on system depth and time. The soil profile is a succession of $10-\mathrm{cm}$ horizontal layers in which water content is determined from water redistribution. In spite of the different approaches, the authors conclude that in their conditions the two models perform equally well.

Despite a few coupling attempts [e.g. 18, 20-22], drainage models are not really crop models. Inversely, most crop models do not correctly predict subsurface drainage rates. Nevertheless, taking subsurface drainage into account in crop models is a good and inexpensive way to test new management practices and to elaborate on agricultural recommendations. With the increasing application of crop models, these tools are beginning to be used as technical aids for decision-making in the areas of agronomy and the environment [5]. In an agricultural context where inputs are limited (for reasons concerning the environment, product quality, etc.) it is difficult to explain the interaction between basic processes without the help of an integrated model. STICS (Simulateur mulTIdisciplinaire pour les Cultures Standard) thereby appears, like many other crop models, to be useful for research on cropping systems and for assessing their agronomic or environmental impacts. STICS is a generic crop growth model constructed as a simulation tool capable of simulating agronomical variables under realistic agricultural conditions. The model is described in detail in Brisson et al. [3, 5]. It simulates crop growth as well as soil water and nitrogen balances driven by daily climatic data. It predicts both agricultural variables (yield and input consumption) and environmental variables (water and nitrogen losses). The formalism used in STICS and the parameter values are largely inspired by the existing literature. This has the advantage of being able to rely on equations that have been validated independently from each other [5].

Two main requirements must be followed to incorporate a subsurface drainage module into the new STICS version 5, as advised by the model designers: (i) the use of simple concepts and introduction of a minimum of new parameters, and (ii) the robustness of the module structure to facilitate subsequent developments.

The objective of this study is to adapt a classical drain-flow model (SIDRA, SImulation du DRAinage, [2, 12]), to the particular water balance scheme of STICS. The modified STICS version 5 was tested against experimental data from a set of agricultural plots in France. This paper focuses on hydraulic aspects rather than cropping management and solute transfers.

\section{THEORY}

\subsection{STICS (version 4) water balance concept in soil}

STICS is a soil-plant-atmosphere model with an atmospheric upper boundary (characterized by standard climatic variables: net radiation, minimum and maximum temperatures, precipitations, reference evapotranspiration or eventually wind and air moisture) and with a soil/subsoil lower boundary. This dynamic model operates on a daily timescale and simulates carbon, nitrogen and water balances of the soil-plant-atmosphere system for various agricultural cases. Data required to run the model relate to climate, soil (water and nitrogen initial profiles and permanent soil features) and crop management.

The soil is described as a vertical succession of layers. Each layer is characterized by water quantity, organic matter and nitrogen content. The model uses the concept of field capacity and introduces two porosity classes. Description of soil includes four compartments: microporosity (or textural porosity), macroporosity (or structural porosity), cracks (in the case of swelling clay soils) and stones. The soil is divided into five horizons but calculations in the microporosity are done per 1-cmthick layer. Water transport in soil micropores is calculated for each 1-cm layer using a tipping bucket approach. Parameters concerning soil hydrodynamic properties are provided for each horizon: field capacity, permanent wilting point, bulk density, stone content and type of stone and infiltrability. Water supplies cascade down, filling up the layers up to field capacity. The permanent features of the 1-cm layers (field capacity, permanent wilting point and bulk density), as well as initial water content, are deduced from those of the 5 horizons describing the soil. The macroporosity and the crack compartments play a role in drainage and run-off processes. For each horizon, a daily infiltration parameter is defined that can limit the amount of infiltrated water, thereby filling up the macropores in the horizon. For non-swelling soils, macroporosity is calculated as usual on the basis of the total porosity (a function of bulk density) and field capacity. Water thereby reaching the horizon above can be used to supply the micropores, before filling the macropores. In those conditions, the STICS version 4 water balance module does not predict subsurface drainage flow.

\subsection{Coupling and adapting the agricultural drainage module}

\subsubsection{SIDRA}

The SIDRA model uses an original approach combining analytical and numerical resolution techniques. An analytical approach leads to spatial integration of Boussinesq's equation. It is based on the assumption of either a constant water table shape allowing the separation of the variables in the Laplace equation, or a time-dependent water table shape. The final differential equation, providing the water table elevation midway between drains, depends only on time and is solved by a simple numerical technique (the Runge-Kutta method). Due to its original approach, the SIDRA model has in addition the advantage 
of accurately simulating peak flows. The model uses hydrometeorological data (rainfall and potential evapotranspiration) as input data and provides the hourly midpoint water table level and drain-flow rate as output data. Depth-dependent soil properties are taken into account by the model. SIDRA introduces the drainable porosity concept that takes into account interactions of the water table with the unsaturated zone. The drainable porosity $(\mu)$ is defined as the ratio between the volume of water released or stored as the water table moves by unit distance and the volume of drained material affected by the water-table movement.

SIDRA uses net recharge for each time-step and calculates water-table elevation fluctuations at the drain mid-spacing and drain-flow rates. The net recharge is defined as the difference between rainfall and evapotranspiration. The assumption that the net recharge of the water table is equal to the infiltrated rainfall is in generally realistic for wet periods [11]. Drainage design is characterized by a constant spacing between the parallel drains and by the tile depth. The differential equation is derived from Boussinesq's equation and can be written as [2]:

$$
C \cdot \mu \cdot \frac{d H(t)}{d t}=R(t)-J(H)-H(t) \cdot \mu \cdot \frac{d C}{d t}
$$

where $C$ is a water-table shape factor [-], $\mu$ drainable porosity [-], $H(t)$ water-table elevation at drain mid-spacing for the time $t[\mathrm{~L}], R(t)$ net recharge for the time $t\left[{\left.\mathrm{~L} . \mathrm{T}^{-1}\right], J(H) \text { Hooghoudt's }}^{-1}\right.$ function and corresponds to the drain-flow rate in steady state $\left[\mathrm{L} . \mathrm{T}^{-1}\right]$. For more details on the water-table shape factor, see [9].

Hooghoudt's formulation in the case of a drain lying on the impervious barrier, is defined as:

$$
J(H)=\frac{K \cdot H(t)^{2}}{L^{2}}
$$

with $K$, saturated hydraulic conductivity $\left[\right.$ L.T $\left.^{-1}\right]$ and $2 L$, drain spacing [L].

\subsubsection{Boussinesq's equation simplification}

The right term of equation (1) shows that the drain-flow rate can be expressed as the sum of three components. The first term represents the recharge contribution. The second term represents the water-table contribution. The third term corresponds to contribution due to water storage affected by changes in the water-table shape. The relative weight of these three components depends on the drained system properties and on the simulation time-step. Concerning the drained system, Bouarfa and Zimmer [2] showed that a particular combination of parameters determines the relative weight of the three components. Indeed, this factor (called $\sigma$ ) determines how peaky the response of a drainage system is. It is defined as:

$$
\sigma=K /\left(\mu^{2} \cdot L^{2}\right) \quad\left[\mathrm{L}^{-1} \cdot \mathrm{T}^{-1}\right] .
$$

Most French drained soils are usually characterized by a factor $\sigma$ greater than 1: they are called "nervous" and the changes in water-table shape occur very quickly. As a consequence, it can be assumed that water-table deformations have minimal impact on simulations even at the hourly time-step. Thereby in the case of the daily STICS model, the third component on the right- hand side of the equation (1) can be neglected. Hence equation (1) is rewritten as:

$$
C \cdot \mu \cdot \frac{d H(t)}{d t}=R(t)-J(H)
$$

After this first step, the second right-hand term of the right equation (4) is tested. A study of time-step sensibility was done to assess its influence on drain-flow calculation. The simplified approach is compared with the complete model based on the SIDRA model (Eq. (1)). The complete model [2] is based on numerical computation of Boussinesq's equation and calculates the three components of drain flow. The complete model can simulate drain-flow rates for different time-steps: 1 hour, $4 \mathrm{~h}, 8 \mathrm{~h}, 16 \mathrm{~h}, 24 \mathrm{~h}$ and $48 \mathrm{~h}$. In comparison, drain-flow rates are computed by different simplified approaches including the two-component equation ( 5 derived from 4$)$ and the one-component $(J(H))$ equation (6 simplified from 5):

$$
\begin{gathered}
Q(t)=A \cdot J(H)+(1-A) \cdot R(t)=A \cdot \frac{K \cdot H^{2}}{L^{2}}+(1-A) \cdot R(t) \\
Q(t)=J(H)=\frac{K \cdot H^{2}}{L^{2}}
\end{gathered}
$$

where $Q(t)$ is drain-flow rate $\left[\mathrm{L} . \mathrm{T}^{-1}\right] ; A$ is a dimensionless water-table shape factor defined as the ratio of the first watertable shape factor $B$ by $C$, the second water-table shape factor $[-] ; R(t)$ net recharge $\left[{\mathrm{L} . \mathrm{T}^{-1}}^{-1}\right.$.

The first and second water-table shape factors $B$ and $C$ are defined analytically in [2], and the third water-table shape factor $C$ is deduced from $A$ and $B$ by the relation: $A=B / C$. For example, in the case of drains lying on the impervious barrier and for steady state the water-table shape is elliptic and $B=\pi /$ $4=0.785, C=0.904$ and $A=0.869$ [24].

Hence, in order to assess the weight of simplification, simplified (Eqs. $(5,6))$ drain-flow rates were used to compare the time-step effect on the quality of the simulation considering two different drained systems: a "nervous" system $\left(\sigma=1.25 \mathrm{~m}^{-1} \cdot \mathrm{h}^{-1}\right)$ and a "slow" system $\left(\sigma=0.05 \mathrm{~m}^{-1} \cdot \mathrm{h}^{-1}\right)$. These values correspond to a range of possible values in land drainage. The highest one $\left(1.25 \mathrm{~m}^{-1} \cdot \mathrm{h}^{-1}\right)$ would correspond to large values of $K$, small values of $\mu$, and small drain spacings (for instance, $K=1 \mathrm{~m} \cdot \mathrm{d}^{-1}$; $\mu=1.9 \%$ and $L=6 \mathrm{~m})$. The lowest one $\left(0.05 \mathrm{~m}^{-1} \cdot \mathrm{h}^{-1}\right)$ would correspond to small values of $K$, large values of $\mu$, and larger drain spacings (for instance $K=0.25 \mathrm{~m} \cdot \mathrm{d}^{-1} ; \mu=3.6 \%$ and $L=$ $8 \mathrm{~m}$ ). We compared the efficiency of complete (which is considered as a reference) and simplified simulated drain-flow rates for each time-step and system. For this theoretical approach, one representative set of data is taken from those described in Section 3.

Moreover, the Nash criterion $e$ [16] is used. It is defined as:

$$
e=1-\frac{\sum_{i=1}^{n}\left(Q_{b_{i}}-Q_{s_{i}}\right)^{2}}{\sum_{i=1}^{n}\left(Q_{b_{i}}-\bar{Q}_{b}\right)^{2}}
$$

where $Q_{b i}$ is the drain-flow rate computed from the complete Boussinesq equation (reference simulation) at time $i, Q_{b}$ the 


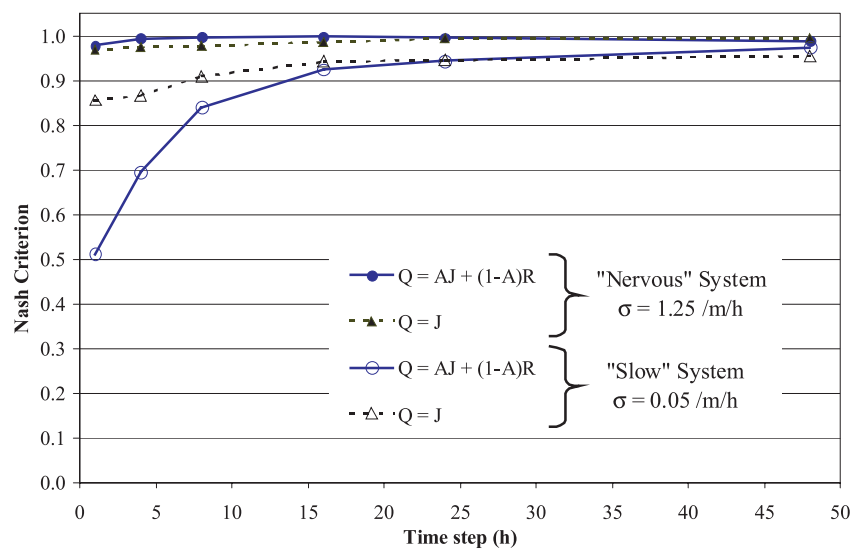

Figure 1. Nash's criterion versus time-step to compare the daily drain-flow rates between the two simplified models and the reference complete model in the case of a "nervous" system and a "slow" system.

corresponding average complete value computed in $n$ time, and $Q_{s i}$ the drain-flow rate computed by one of the two simplified models (Eq. (5) or (6)). The greater the consistency between the two simulated sequences (complete and simplified), the higher the Nash criterion would be. It reaches 1 when both sequences are identical.

Figure 1 presents the Nash criterion values versus time-step. The curve of the "slow" response system $\left(\sigma=0.05 \mathrm{~m}^{-1} \cdot \mathrm{h}^{-1}\right)$ shows two parts. For small time-steps, simplified models differ from the complete model. Calculated Nash criterions are below 0.9 . This kind of system does not generate high peak-flow rates. The "net recharge" term in equation (5) and water-table shape changes cannot be neglected for small time-steps. Water-table recharge contributes to inflating the water-table shape and mitigates its effects on the drain-flow rate. Nevertheless, the Nash criterion is improved with increasing time-steps. For $24 \mathrm{~h}$ the output data for simplified and complete models are almost the same $(e>0.94)$.

For the "nervous" system, both kinds of calculation are close for each time-step (Nash criterion values between 0.97 and 1). Fast-response systems $\left(\sigma=1.25 \mathrm{~m}^{-1} \cdot \mathrm{h}^{-1}\right)$ generate high peak flows because of the quick inflating/deflating processes of the water table. In such systems, peak-flow values largely exceed the transient recession stage $A(t) . J(t)$ component. Besides, at a daily time-step, water-table shape changes are fast enough to be neglected in the computations so that drain-flow rates can be evaluated by equation (5) or (6).

We conclude that in both cases (nervous and slow systems) errors due to simplified equations (5) and (6) decrease ( $e$ greater than 0.9) when the time-step increases ( $t$ greater than $16 \mathrm{~h})$. Concerning STICS adaptation, this daily time-step is supposed to be acceptable and STICS drain-flow rates calculation uses the simplest expression: equation (6).

\subsection{Effective incorporation of the drainage module into the STICS model}

The previousSTICS version 4 did not take into account subsurface drainage. Water in excess in the soil profile is directly

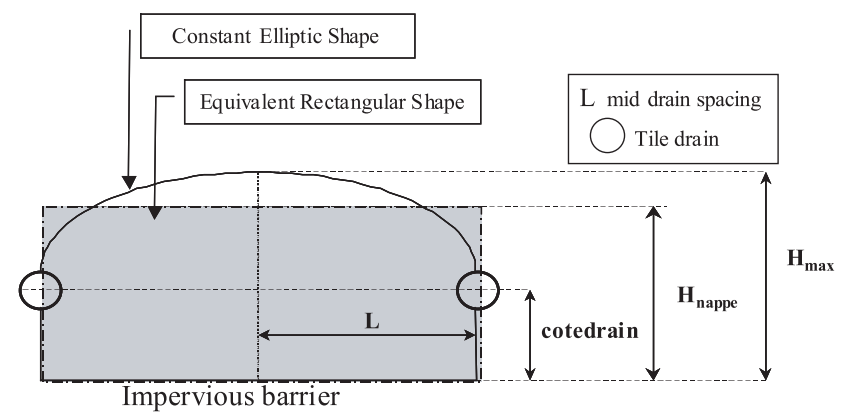

Figure 2. Conceptual scheme of drained shallow water table in soil profile.

evacuated as surface runoff. Our adaptation is based on the calculation of an equivalent drain-flow rate and on integrating this water quantity into a new final water balance. This operation needs two steps: (1) dimensional coupling (to transform the two-dimensional drained system SIDRA model into a onedimensional plot-scale column system) and (2) time coupling (to transform the hourly SIDRA time-step into the daily STICS time-step) including new concepts. In the following, the variables are those used in STICS.

\subsubsection{Dimensional coupling}

To transform the 2D drained hydraulic functioning into a 1D column system, the concept of equivalent drainage behavior is introduced by way of an average water table elevation $\left(H_{\text {nappe }}\right)$, shown in Figure 2. This approach is similar to those developed in the AGRIFLUX model [1]. The general shape of the watertable elevation between drain area and mid-drain spacing could be assumed to be constant. This entails that the shape draws a semi-ellipse (in the case of drains lying on the impervious layer). Considering the first water-table shape factor (B) as constant, the area of the semi-ellipse, in a two-dimensional watertable representation, must be identical to the area of the rectangle in the one-dimensional STICS representation. This average water-table elevation $\left(H_{\text {nappe }}\right)$ is mathematically linked to the mid-drain spacing water-table elevation $\left(H_{\max }\right)$ by integrating the water-table elevation function depending on the distance from the mid-drain spacing to the drain, as:

$$
H_{\text {max }}=\frac{H_{\text {nappe }}-\text { cotedrain }}{\text { Bformnappe }}
$$

in which "cotedrain" is the measured tile-drain elevation [L] and Bformnappe is the first water-table shape factor $(B=0.785$, drains lying on the impervious layer) [-].

The dimensional coupling needs to add complementary assumptions. First, the drainable porosity $(\mu)$ is supposed to be equal to the macroporosity compartment of the STICS model ("calmacro"). When gravity flows appear after microporosity saturation in the soil, water fills the macroporosity up and defines an equivalent shallow water table. The roof of the water table is equal to the highest level of the layer in which the macroporosity is waterlogged. This height corresponds to the average water table $H_{\text {nappe }}$. Fixing the value of the drainable 
porosity (see Sect. 2.3.4), equation (9) allows the calculation of the other water contents (field water capacity hcc):

$$
\begin{gathered}
h c c(n h)=\left[\left(\frac{1-d a(n h)}{2.66}\right)\right. \\
\left.-\left(\text { calmacro } \cdot \frac{1}{10 \cdot \text { epc }(n h)}\right)\right] \cdot \frac{100}{d a(n h)}
\end{gathered}
$$

where epc(nh): depth of soil layer of the soil horizon $n h[\mathrm{~L}]$; $d a(n h)$ : bulk density of the soil horizon $n h\left[\mathrm{M} \cdot \mathrm{L}^{-3}\right]$.

Secondly, the lower boundary in the last soil horizon is supposed to be an impervious barrier fixing a low value (close to zero) of the hydraulic conductivity $(\mathrm{ksol})$.

The average water-table elevation $\left(H_{\text {nappe }}\right)$ is assimilated to the excess level profile obtained by the STICS model considering water excess that fills and circulates into macroporosity (see Sect. 2.1).

\subsubsection{Time coupling}

For every daily time-step (Sect. 2.2.2), an average watertable elevation is calculated and maximum water-table elevation at mid-drain spacing $\left(H_{\max }\right)$ is deduced (Eq. (8)). With the drained system parameters, and $H_{\text {max }}$, a drained water quantity (assimilated to the drain-flow rate) is calculated, eventually including some exchanges between successive horizons according to the following expression (derived from Eq. (6)):

$$
\text { qdrain }=\frac{\mathrm{ksol} \cdot H_{\max }^{2}}{\text { ldrain }^{2}} \cdot 10
$$

where qdrain: drain-flow rate [L. $\left.\mathrm{T}^{-1}\right]$; $k$ sol: hydraulic conductivity $\left[\mathrm{L} . \mathrm{T}^{-1}\right] ; H_{\max }$ : maximal water-table level at mid-drain spacing [L]; ldrain: semi-drain spacing [L]; 10: conversion coefficient.

\subsubsection{Algorithm}

Both couplings were integrated into the STICS algorithm by adding the module to a subroutine, LIXIV.FOR, of the STICS model. The subroutine LIXIV.FOR manages water and nitrogen transport in the soil profile: for each daily time-step, a drain-flow rate is estimated and withdrawn from the soil column. The drained water amount is removed from water contained in the macroporosity. Thereby a new average water-table elevation is determined in the soil profile by redistribution of water moving upwards in the soil profile (Fig. 3).

\subsubsection{Parameter determination}

Model parameters can either be measured in situ during drainage project planning, or calibrated on experimental drainflow recession curves, or on experimental drain-flow rates and water-table elevation sequences. Field effective and depthdependent values of hydraulic conductivity and drainable porosity are seldom available [25]. A few methods are available [14] including Guyon's pumping test [6] that, although lengthy to implement, appears to be the most accurate method. In French subsurface drained soils, drainable porosity ranges generally between 1 and $8 \%$. The order of magnitude of drainable porosity and saturated hydraulic conductivity could be deter-

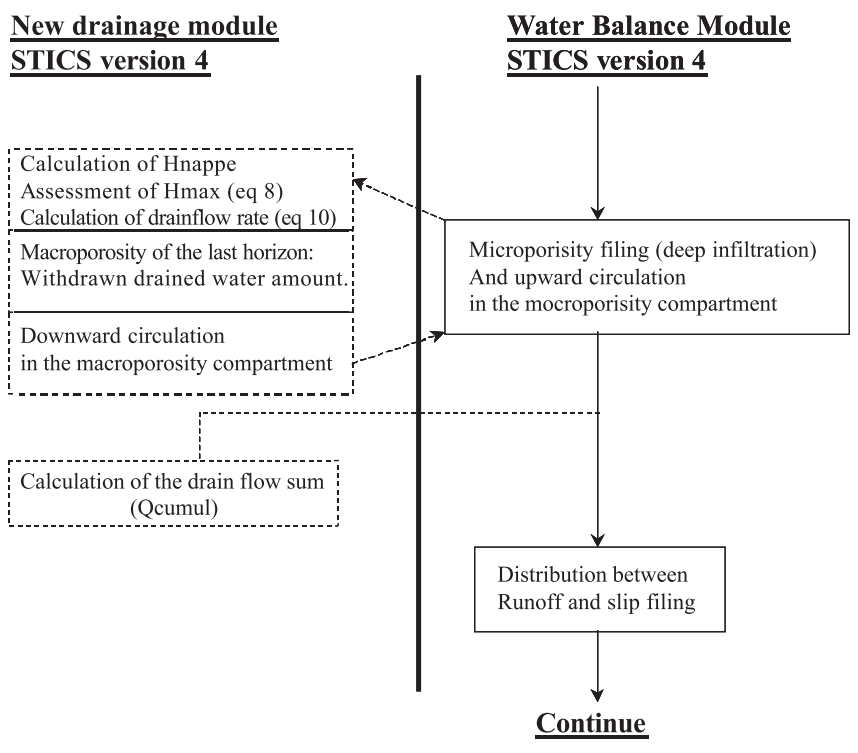

Figure 3. Integration of the drainage module in subroutine LIXIV.FOR (dashed line shows the pathway when drainage module is activated).

mined by the STICS users by taking into account a simplified soil typology and corresponding data available in Table I. Table I gathers soil types that are mainly represented in France.

\section{TEST METHODOLOGY: EXPERIMENTAL DATA USED}

To assume practical applications of the model, no attempt to calibrate parameters was carried out. Outputs provided by the modified STICS model were compared with water-table depths, drain-flow rates and cumulated drainage volumes measured on a set of experimental plots. In order to test the model, water balances were compared and Nash's criterion was used.

The monitored plots were in the experimental site in Arrou [12], located in the southwest of the "Bassin Parisien". The Arrou site included eight experimental plots of about 2 hectares. Seven of them were equipped with drains with different spacings (see Tab. II), and one undrained control plot. Drained flows in some plots had been measured using calibrated overflow containers (V-notch weirs) in which water height was recorded at hourly time-intervals. Observation wells had been

Table I. Value of drainable porosity and saturated hydraulic conductivity according to mainly French soil textures.

\begin{tabular}{lcc}
\hline Soil texture & Drainable porosity value & $\begin{array}{c}\text { Saturated hydraulic } \\
\text { conductivity }\end{array}$ \\
\hline Sandy & $6-8 \%$ & $5-10 \mathrm{~m} \cdot \mathrm{d}^{-1}$ \\
Loamy & $3-4 \%$ & $1 \mathrm{~m} \cdot \mathrm{d}^{-1}$ \\
Clay & $1-4 \%$ & $0.01-0.1 \mathrm{~m} \cdot \mathrm{d}^{-1}$ \\
\hline
\end{tabular}


Table II. Characteristics of the measured plots, Arrou, France.

\begin{tabular}{lcccc}
\hline Plot & Surface (ha) & Drain spacing $(\mathrm{m})$ & Year & Crop \\
\hline 1 & 2.006 & 10 & $85-86$ & Wheat \\
6 & 2.004 & 10 & $78-79$ & Wheat \\
6 & 2.004 & 10 & $79-80$ & Corn \\
6 & 2.004 & 10 & $81-82$ & Wheat \\
6 & 2.004 & 10 & $82-83$ & Corn \\
2 & 2.006 & 15 & $80-81$ & Rye grass \\
8 & 2.004 & 20 & $81-82$ & Wheat \\
8 & 2.004 & 20 & $82-83$ & Wheat \\
\hline
\end{tabular}

set up in the plots and automatically monitored the water-table height. The hourly data were used to obtain the daily values (total daily drain-flow rate, mean daily water-level elevation). The soil is a luvisol with a silty-clayey texture to a depth of $0.50 \mathrm{~m}$ and then clayey-silty from 0.50 to $1.30 \mathrm{~m}$. The depth of the impervious layer is considered to be $0.80 \mathrm{~m}$. Soil properties are supposed to be similar for all plots. The values of drainable porosity and mean hydraulic conductivity are, respectively, $3 \%$ and $30 \mathrm{~cm} \cdot \mathrm{d}^{-1}$ [13]. Tests were done for several situations (crop and drain spacing over several years) for which data were available. As shown in Table II, the plots were conducted under maize, winter wheat or rye grass. Conventional tillage practices, consisting of a sequence of moldboard plow, harrow and rotary hoe, were adopted in the plots. Comparison was focused on the well-known intensive drainage season. Generally in subdrainage monitoring, four periods are distinguished in the whole drainage season. The first drain-flow rates correspond to the beginning of the drainage season. The second period is the intensive drainage season (almost all "net recharges" are converted into drain-flow rates). The third period corresponds to the end of the drainage season, and the fourth period corresponds to springtime drainage, which occurs for a few springtime events. The main points to check are the first drainage events (when water soil storage capacity starts to get full) and the total discharge during the intensive drainage season.

\section{RESULTS AND DISCUSSION}

Table III summarizes the statistical results of the simulations. For the intensive drainage season, the observed amount of precipitations and discharge are shown. In most cases, simulated drain-flow rates agree with the observed data. For each simulation, Nash's Criterion $e$ was computed from predicted and measured drain-flow rate values, restricted to the intensive drainage season. This method is justified because the simulations are thus independent of the initial conditions and drainflow rates are generally null the rest of the year. Analysis of Nash's Criterion $e$ raises two points. With $e$ greater than 0.5 (between 0.56 for plot 6, 1982-1983, and 0.77 for plot 6, 19811982), the model shows an acceptable accuracy with the observed drain-flow rate. However, for the large drain spacing (20 $\mathrm{m}$ in plot 8$)$, criterion $e$ is less than 0.5 (0.01 and 0.25 , respectively, for 1981-1982 and 1982-1983) whereas for plot 6 , criterion $e$ is equal to 0.77 and 0.56 for the same years. In this particular case, the model does not predict the drain-flow rate accurately. It is probably due to constant values of the drainage parameters (the water-table shape factor and drainable

Table III. Statistical results of the simulated and observed data for the Arrou survey, 1979-1983 and 1985-1986 (P: precipitation; $\Sigma$ Qobs:

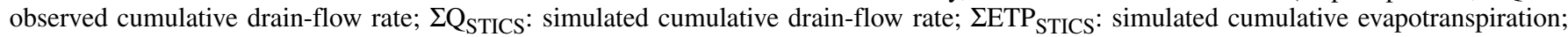
$\Sigma \mathrm{R}_{\text {STICS }}$ : simulated cumulative runoff; $\mathrm{WB}=\Sigma \mathrm{Q}_{\text {STICS }}+\Sigma \mathrm{ETP}_{\text {STICS }}+\Sigma \mathrm{R}_{\text {STICS }}$ : simulated water-balance value; error WB $=\mathrm{P}-\mathrm{WB}$ : error between observed precipitation and simulated water balance; error TotalQ ( $\mathrm{mm}$ and \%): error calculated between total observed drain-flow rates and total simulated drain-flow rates, respectively, in $\mathrm{mm}$ and in percentage; $\mathrm{e}_{\mathrm{Q}}$ : Nash's criterion $e$ computed on daily drain-flow rates).

\begin{tabular}{|c|c|c|c|c|c|c|c|c|c|c|c|c|}
\hline Plot & Year & $\begin{array}{c}\text { Intensive } \\
\text { drainage season }\end{array}$ & $\begin{array}{l}\text { Precipitation } \\
\mathrm{mm}\end{array}$ & $\begin{array}{c}\Sigma \mathrm{Q}_{\mathrm{obs}} \\
m m\end{array}$ & $\begin{array}{c}\Sigma \mathrm{Q}_{\text {STICS }} \\
\text { mm }\end{array}$ & $\underset{\mathrm{mm}}{\Sigma \text { ETP }_{\text {STICS }}}$ & $\begin{array}{c}\Sigma \mathrm{R}_{\text {STICS }} \\
\mathrm{mm}\end{array}$ & $\begin{array}{l}\mathrm{WB} \\
\mathrm{mm}\end{array}$ & error WB & $\begin{array}{l}\text { error TotalQ } \\
\text { mm }\end{array}$ & $\begin{array}{c}\text { error TotalQ } \\
\%\end{array}$ & $e_{\mathrm{Q}}$ \\
\hline 6 & 78 & $\begin{array}{c}01 / 19 / 79- \\
04 / 10 / 79\end{array}$ & 221.3 & 200.28 & 184.35 & 39.3 & 0 & 223.65 & $-1.06 \%$ & 15.93 & $7.95 \%$ & 0.7642 \\
\hline 6 & 79 & $\begin{array}{c}12 / 09 / 79- \\
04 / 01 / 80\end{array}$ & 315.6 & 206 & 249.14 & 55.35 & 1.44 & 305.93 & $3.06 \%$ & -43.14 & $-20.94 \%$ & 0.6341 \\
\hline 6 & 81 & $\begin{array}{l}12 / 15 / 81- \\
01 / 21 / 82\end{array}$ & 144 & 138 & 128 & 15.8 & 0 & 143.8 & $0.14 \%$ & 10 & $7.25 \%$ & 0.7743 \\
\hline 6 & 82 & $\begin{array}{c}12 / 06 / 82- \\
05 / 14 / 83\end{array}$ & 375 & 227 & 277.9 & 81.9 & 19.8 & 295.35 & $1.21 \%$ & -50.9 & $-22.42 \%$ & 0.5667 \\
\hline 1 & 85 & $\begin{array}{c}02 / 24 / 86- \\
04 / 27 / 86\end{array}$ & 103.8 & 44 & 57.5 & 42.17 & 0 & 99.67 & $3.98 \%$ & -13.5 & $-30.68 \%$ & 0.3848 \\
\hline 2 & 80 & $\begin{array}{l}12 / 20 / 80- \\
03 / 28 / 81\end{array}$ & 227 & 146 & 171 & 47.63 & 6.94 & 225.57 & $0.63 \%$ & -25 & $-17.12 \%$ & 0.6285 \\
\hline 8 & 81 & $\begin{array}{c}12 / 15 / 81- \\
01 / 26 / 82\end{array}$ & 131 & 61 & 98.6 & 15.11 & 19.9 & 133.61 & $-1.99 \%$ & -37.6 & $-61.64 \%$ & 0.0176 \\
\hline 8 & 82 & $\begin{array}{l}12 / 06 / 82- \\
04 / 11 / 83\end{array}$ & 285 & 113 & 161 & 79.01 & 56.01 & 296.02 & $-3.87 \%$ & -48 & $-42.48 \%$ & 0.2512 \\
\hline
\end{tabular}




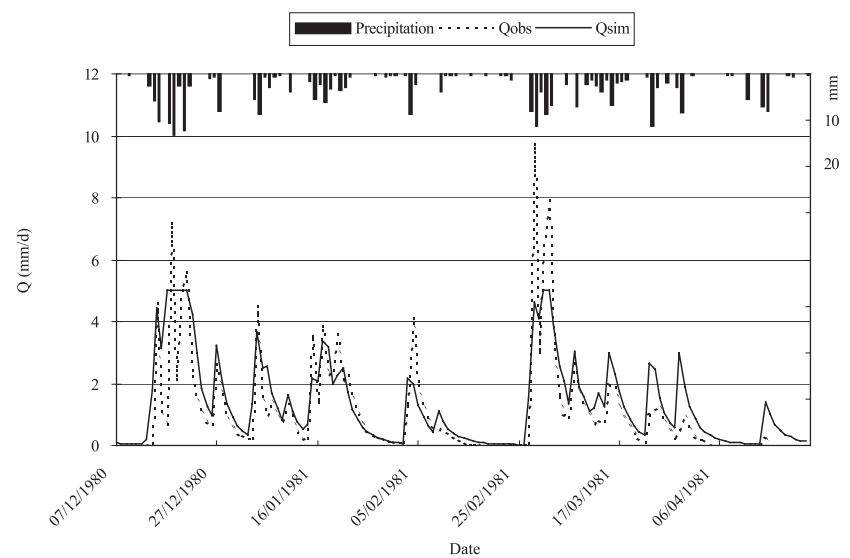

Figure 4. Daily simulated (Qsim) and observed (Qobs) drain-flow rate $\left(\mathrm{mm} \cdot \mathrm{d}^{-1}\right)$ curves for Plot $2(\mathrm{~L}=15 \mathrm{~m}), 1980-1981$, and precipitation curve.

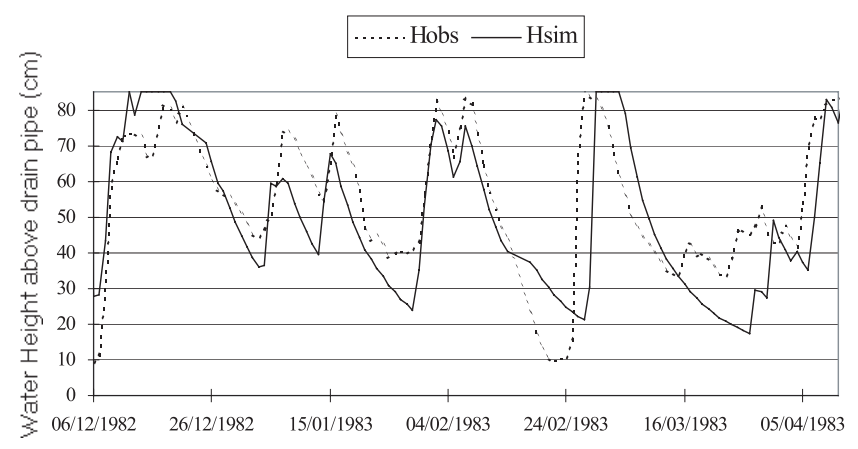

Figure 5. Daily simulated (Hsim) and observed (Hobs) water-table elevation above drain pipe $(85 \mathrm{~cm}$ depth) for Plot $8(\mathrm{~L}=10 \mathrm{~m})$, 1982-1983.

porosity non-applicable for longer distances) used in the simplified model. As an example, observed and simulated curves for plot 2, year 1980-1982 are reported in Figure 4. The estimated values are very close to the observed ones.

A detailed analysis of Figure 4 reveals that for the whole intensive drainage season, discrepancy between measured and estimated data is greatest for peak flows, and the simulated drain-flow rate cannot exceed a limit, which is determined by the maximum water-storage amount in the soil profile depending on the drainage parameters. For all simulation cases, the model predicts water-level elevation accurately. From a qualitative point of view and in spite of drain volume discrepancy between measured and observed values for plot 8, the simulated water-table elevation above the drain, Figure 5, shows a trend in accordance with the observed data. This point underlines STICS' ability to assess interaction between crop root development and waterlogged conditions. The crop influence is also evaluated for plot 6 [1978 to 1982]. Nash's criterion is higher in the case of winter wheat $(0.76$ and 0.77 , respectively, for 1978 and 1981) than in the case of corn (0.63 and 0.56, respectively, for 1979 and 1982). Before the corn sowing date (in May), there is no cover and the plot soil is assumed to be bare. The error could be attributed to a bad estimation of the soil

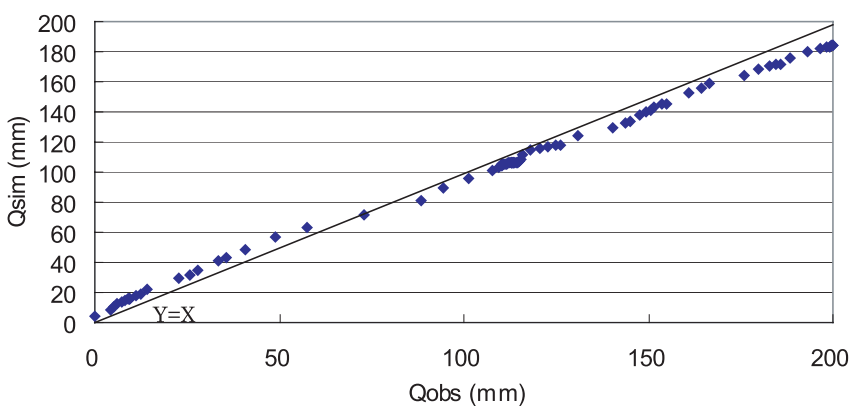

Figure 6. Cumulative simulated drain-flow rate versus cumulative observed drain-flow rate for intensive drainage season of Plot $6(\mathrm{~L}=$ 10 m), 1979-1980.

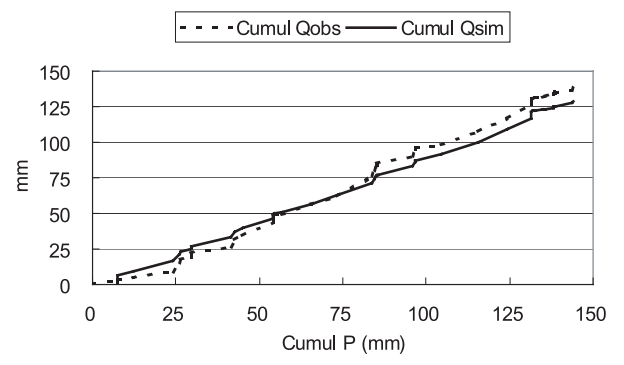

Figure 7. Double cumulative curves: cumulative simulated (Cumul Qsim) and observed (Cumul Qobs) drain flow rates and cumulative precipitation for intensive drainage season of Plot $6(\mathrm{~L}=5 \mathrm{~m}), 1981$ 1982 .

evaporation. Nevertheless, for a bare soil, interactions between the crop and waterlogged conditions do not exist.

Simulated water-balance terms (simulated Runoff, Discharge and ETP) are presented for different situations (plot, crop and year) and the sums are compared with total precipitation for the same period. The error between the simulated water balance and observed precipitation (error WB) is inferior to $4 \%$. Concerning the comparison of cumulative observed and simulated drainage discharge, the double cumulative curve and observed versus simulated curve are used to assess the performance of the simulation (Figs. 6, 7). It confirms that the modified STICS model predicts water balance for subsurface drained soils with an acceptable error.

On the whole, the statistical analysis of simulated and observed data, as shown in Table III, reveals that the model is able to predict observed drain-flow rates with a good accuracy. Excess water input generates drain-flow rates. Recession tails are also well simulated. Initial conditions are crucial to correctly predict first drainage events. Nevertheless, this study highlights three main problems in the model. Peak flows are not well simulated, mainly due to the simplification of equation (6). Otherwise the model reaches its limits in the case of large drain spacings (greater than $20 \mathrm{~m}$ ). However, in the French context, drain spacing is most of the time between 10 and $15 \mathrm{~m}$. A third drawback of the model concerns spring episodes that are apparently badly simulated. It is generally linked to rainfall intensity, fugacity and other non-drainage parameters. A daily time-step is not appropriate in these cases. The validation study shows 
that model performances are linked to the considered crop. We conclude that the modified STICS model presented herein is acceptable for drain spacings of less than $20 \mathrm{~m}$ and for a winter crop or cover.

\section{CONCLUSION}

The new version 5 of STICS needed to adapt the classical approach to integrating a subdrainage module, reaching the objectives of simple, robust and modular formulation. Therefore approximate methods are preferred and used to simulate drain-flow rate to avoid prohibitive computer times for longterm simulations due to the application of numerical solutions to non-linear differential equations. Concerning subsurface drainage, Hooghoudt's equation is widely used to estimate drain-flow rates in steady state: we have shown that for a sufficiently long time-step (greater than $16 \mathrm{~h}$ ), this simplified equation provides correct prediction of flow rates and watertable heights. The SIDRA model [12] was thus adapted to a daily time-step. Besides introducing agricultural drainage into the STICS model, the main difficulty lies in a realistic waterbalance management compatible with subsurface drainage modeling. For the dimensional aspect, the passage from the 2D or pseudo-2D classical approach to STICS conceptualization is done by taking the equivalent water elevation between the drain and mid-drain spacing. Its value depends on a parameter (B or Bformnappe in STICS) that is defined as a water-table shape factor and the analogy between the STICS defined macroporosity parameter and the classical drainable porosity $(\mu)$. Drain-flow rates are calculated, hence the equivalent water amount is withdrawn from the soil profile, and finally a new water-table elevation is defined. This new original drainage module has been included in the STICS version 4.0 algorithm. This hydraulic aspect leads to the adaptation of STICS including geometrical, water-balance calculation and time discretization aspects.

The STICS approach needs a minimum of new parameters. Drainage parameters were introduced. Geometrical parameters such as drain spacing and depth of drain pipe are obvious input parameters. The conceptual hydraulic parameter B (Bformnapp) is supposed to be equal to 0.785 (assuming that the drains rest on an impervious layer), [12]. Hydraulic conductivity $(\mathrm{Ksol})$ has to be measured in the field or determined from laboratory experiments. Determination of the drainable porosity is indirect. From the value in Table I, a new humidity field capacity is calculated (Eq. (8)).

These theoretical results have been tentatively validated in the field experiment of Arrou (France). The model provides the daily drain-flow rate, daily water-table elevation, and cumulative drain-flow rate. Simulations were conducted between the years 1978 and 1986 under different crops (wheat, corn and rye grass) and different drain spacing $(10,15,20 \mathrm{~m})$ in plots. On the whole, the simulations are in a good agreement with the observed data. Recession tails are well reproduced. Nash's Criterion confirms the relative accuracy of the model. For the intensive drainage season, the water-balance calculation and cumulative drain-flow rate comparison led to acceptable precision. Moreover, this study underlines the model's limits in predicting peak-flow events for large drain spacings and bare soils.

Further work should be carried out to extend this concept. Indeed, these results should allow the integration of waterlogged consequences on crops (growth and yield). Interaction functions between the water level and crop roots' activities have been introduced in [4] and should be incorporated into STICS version 5.0. These perspectives should take into account water stress on wheat, and solute transport under waterlogged conditions.

Acknowledgements: The authors thank the STICS team (Dr. N. Brisson and D. Ripoche, from INRA) for their help with incorporating the subsurface drainage module into the STICS algorithm.

\section{REFERENCES}

[1] Banton O., Larocque M., AgriFlux 2.0: Manuel d'utilisation. Logiciel d'évaluation des pertes environnementales de nitrates et pesticides agricoles. INRS-Eau, Université du Québec, 1997, $145 \mathrm{p}$.

[2] Bouarfa S., Zimmer D., Water-table shapes and drain flow rates in shallow drainage systems, J. Hydrol. 235 (2000) 264-275.

[3] Brisson N., Mary B., Ripoche D., Jeuffroy M.H., Ruget F., Nicoullaud B., Gate P., Devienne-Barret F., Antonioletti R., Durr C., Richard G., Beaudoin N., Recous S., Tayot X., Plenet D., Cellier P., Meynard M., Delécolle R., STICS: a generic model for the simulation of crops and their water and nitrogen balances. I. Theory and parametrization applied to wheat and corn, Agronomie 18 (1998) 311-346.

[4] Brisson N., Rebière B., Zimmer D., Renault P., Response of the root system of a winter wheat crop to waterlogging, Plant Soil 243 (2002) 43-55.

[5] Brisson N., Gary C., Justes E., Roche R., Mary B., Ripoche D., Zimmer D., Sierra J., Bertuzzi P., Burger P., An overview of the crop model, Eur. J. Agron. 18 (2003) 309-332.

[6] Dorsey J.D., Ward A.D., Fausey N.R., Bair E.S., A Comparison of 4 Field Methods for Measuring Saturated Hydraulic Conductivity, Trans. ASAE 33 (1990) 1925-1931.

[7] El-Sadek A., Feyen J., Berlamont J., Comparison of models for computing drainage discharge, J. Irrig. Drain. Eng. 127 (2001) 363-369.

[8] French Ministry of Agriculture and Fishery. 2001. Analyse de l'évolution des aménagements hydro-agricoles pour la période 1980-1996, Ed. Cemagref, DERF, MAP, 9 p. + Annexes (in French).

[9] Hartani T., Zimmer D., Lesaffre B., Drainage of sloping lands with variable recharge: Analytical formulas and model development, J. Irrig. Drain. Eng. 127 (2001) 8-15.

[10] Kabat P., van den Broek J.B., Feddes R.A., WACROP: a water management and crop production simulation model, I.C.I.D. Bull. 41 (1992) 61-64.

[11] Kao C., Bouarfa S., Zimmer D., Steady state analysis of unsaturated flow above a shallow water-table aquifer drained by ditches, J. Hydrol. 250 (2001) 122-133.

[12] Lesaffre B., Zimmer D., Subsurface Drainage Peak Flows in Shallow Soil, J. Irrig. Drain. Eng. 114 (1998) 387-406

[13] Lesaffre B., Fonctionnement hydrologique et hydraulique du drainage souterrain des sols temporairement engorgés : débits de 
pointe et modèle SIDRA, Ph.D. Thesis, Université Paris VI, 1988, 334 p. (in French).

[14] Lesaffre B., Field measurement of saturated hydraulic conductivity and drainable porosity using Guyon's pumping test, Trans. ASAE 33 (1990) 173-178.

[15] Lorre E., Lesaffre B., Skaggs R.W., Comparison of Models for Subsurface Drainage in Flat and Sloping Lands, J. Irrig. Drain. Eng. 120 (1994) 266-277.

[16] Nash J.E., Sutcliffe J.V., River flow forecasting through conceptual models, J. Hydrol. 10 (1970) 282-290.

[17] Penel M., Conduites des céréales en conditions d'excès d'eau : l'hydraulicien et l'excès d'eau, Perspect. Agric. 126 (1988) 22-30 (in French).

[18] Reyes M.R., Bengtson R.L., Fouss J.L., GLEAMS-WT hydrology submodel modified to include subsurface drainage, Trans. ASAE 37 (1994) 1115-1120.

[19] Robinson M., Impact of improved land drainage on river flows, Institute of Hydrology Report No. 113, Wallingford UK, 226 p. (1990).
[20] Sabbagh G.J., Fouss J.L., Bengtson R.L., Comparison of EPICWT and DRAINMOD simulated performance of land drainage systems, Trans. ASAE 36 (1993) 73-79.

[21] Sarwar A., Bastiaanssen W.G.M., Boers T.H.M., Van Dam J.C., Evaluating drainage design parameters for the fourth drainage project, Pakistan by using SWAP model: Part I - calibration, Irrig. Drain. Syst. 14 (2000) 257-280.

[22] Singh P., Kanwar R.S., Modification of RZWQM for simulating subsurface drainage by adding a tile flow component, Trans. ASAE 38 (1995) 489-498.

[23] Skaggs R.W., A water management model for artificially drained soils. North Carolina University State, Raleigh, 1980, 54 p.

[24] van Dam J.C., Huygen J., Wesseling J.G., Feddes R.A., Kabat P., van Walsum P.E.V., Groenendijk P., van Diepen C.A., Theory of SWAP version 2.0; simulation of water flow, solute transport and plant growth in the Soil / Water / Atmosphere / Plant environment, Wageningen Agricultural University and DLO Winand Staring Centre, Wageningen, 1997.

[25] Zimmer D., Lorre E., Lesaffre B., Parameter sensivity and field evaluation of SIDRA model, Irrig. Drain. Syst. 9 (1995) 279-296. 